Disponível em

http://www.anpad.org.br/rac

RAC, Rio de Janeiro, v. 18, n. 4, art. 5, pp. 465-486, Jul. /Ago. 2014

http://dx.doi.org/10.1590/1982-7849rac20141512

$($ co) EY-No

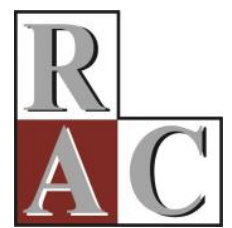

\title{
Avaliação do Ensino de Empreendedorismo entre Estudantes Universitários por meio do Perfil Empreendedor
}

Evaluation of Teaching Entrepreneurship among University Students by Means of an Entrepreneur Profile

Estevão Lima de Carvalho Rocha

E-mail: estevao.lcr@gmail.com Universidade Estadual do Ceará - UECE Av. Paranjana, 1700, Campus do Itaperi, 60714-903, Fortaleza, CE, Brasil.

Ana Augusta Ferreira Freitas

E-mail: freitas8@terra.com.br Universidade Estadual do Ceará - UECE Av. Paranjana, 1700, Campus do Itaperi, 60714-903, Fortaleza, CE, Brasil.

Artigo recebido em 27.06.2013. Última versão recebida em 22.04.2014. Aprovado em 08.05.2014. 


\title{
Resumo
}

O empreendedorismo é um fenômeno socioeconômico que tem sido valorizado em virtude da sua influência no crescimento e desenvolvimento de economias regionais e nacionais. O principal agente promotor desse fenômeno é o empreendedor, sujeito dotado de múltiplas características que compõem seu perfil e que atua de uma forma dinâmica e voltada para colher resultados, frutos de seus esforços pessoais. A educação empreendedora é destacada como uma das formas mais eficientes de se divulgar a cultura e formar novos empreendedores. Observa-se, entretanto, certa dificuldade de se avaliar a eficiência do ensino-aprendizagem desse tema. Assim, o objetivo deste estudo foi analisar, por meio de técnicas multivariadas, um instrumento que tem como função mensurar a aprendizagem do ensino de Empreendedorismo, nesse sentido, verificando a alteração do perfil empreendedor entre 407 estudantes universitários participantes e não participantes do processo de formação empreendedora. Os resultados evidenciaram que os estudantes que participaram de atividades educacionais de formação em Empreendedorismo apresentaram alterações significativas no perfil empreendedor. As principais contribuições mostram crescimento nas dimensões Autorrealização, Planejador, Inovador e Assume riscos no perfil estudado.

Palavras-chave: empreendedorismo; formação empreendedora; perfil empreendedor.

\begin{abstract}
Entrepreneurship is a socioeconomic phenomenon that has been valued for its influence on the growth and development of regional and national economies. The main promoter of this phenomenon are entrepreneurs, subjects endowed with multiple features that make up their profiles. They are dynamic and results oriented, benefitting from the fruits of their own personal efforts. Entrepreneurial education is highlighted as one of the most efficient ways to promote an entrepreneurial culture and train new entrepreneurs. However, some difficulty has been observed in assessing the effectiveness of teaching and learning this subject. The objective of this study was to analyze, by means of multivariate techniques, an instrument whose function is to measure the learning of Entrepreneurship, verifying the change in entrepreneur profiles of 407 college students participating or not in an entrepreneurial training process. The results showed that students who participated in Entrepreneurship educational training activities showed significant changes in their entrepreneurial profiles. The main contributions showed growth in the Self-realization, Planner, Innovative and Risks Assumed dimensions.
\end{abstract}

Key words: entrepreneurship; entrepreneurial education; entrepreneur profile. 


\section{Introdução}

O empreendedorismo é um tema que vem sendo explorado em diversas pesquisas devido ao papel que desempenha na economia e no desenvolvimento de regiões e países. Este papel está associado a uma característica peculiar desse fenômeno, que se trata da criação de novos negócios por sujeitos empreendedores (Degen; 2009; Hisrich, Peters, \& Shepherd, 2009; Martes, 2010). Os empregos e a geração de renda criados a partir da abertura de novas empresas tornam o empreendedorismo um destacado fenômeno socioeconômico, o que desperta o interesse de governos e sociedades que buscam alternativas de políticas públicas com vistas a combater o desemprego e gerar crescimento econômico.

O arcabouço teórico-empírico constituído sobre o tema aponta que os sujeitos empreendedores apresentam características e comportamentos comuns (Casson, 1982). Dessa forma, como agentes benéficos para o crescimento, geram emprego e renda, a presença destes indivíduos nas sociedades tem sido considerada um fator positivo, motivando ações governamentais para ampliá-la (Dornelas, Timmons, \& Spinelli, 2010; Filion, 1999). Murphy, Liao e Welsch (2006) destacam o papel preponderante do sujeito empreendedor na concepção do empreendedorismo. Nessa perspectiva, a educação empreendedora tem focado uma de suas correntes no ensino do Empreendedorismo a estudantes do ensino superior, destacando-se o curso de Administração, em razão da interface entre inovação, oportunidade, gestão e desenvolvimento econômico (Acs, 2006; Degen, 2009). Com isso, diversos processos pedagógicos têm sido aplicados, resultando na criação das atividades educacionais de formação em empreendedorismo (AEFE). Estas AEFE consistem em palestras, recomendações de leituras, estudos de caso, visita a empresas, brainstorming, simulações e projetos desenvolvidos em grupos (Henrique \& Cunha, 2008), assim como planos de negócios, entrevistas com empreendedores, uso de filmes (Kuratko, 2005) e jogos sobre empreendedorismo (Ruskovaara, Pihkala, Rytkölä, \& Seikkula-Leino, 2010).

Acerca da proliferação de estudos sobre o tema, Honig (2004) coloca que, apesar da grande quantidade de pesquisas que relacionam a educação empreendedora e as intenções empreendedoras, discordâncias teóricas e empíricas mantêm-se. Na tentativa de compilar resultados de estudos desta natureza, algumas recentes análises foram conduzidas (Bae, Qian, Miao, \& Fiet, 2014; Martin, McNally, \& Kay, 2013) e comprovaram a existência de uma relação positiva, embora pequena, entre a educação empreendedora e as intenções empreendedoras. O presente estudo segue a tradição de pesquisa empreendedora baseada em evidências, trazendo como contribuição acadêmica a discussão sobre a educação empreendedora e o perfil empreendedor. Ao focar no perfil empreendedor, e não na intenção empreendedora, pretende-se contornar limitações reconhecidas (e.g. Boyles, 2012) de que a intenção empreendedora não é a variável mais adequada à análise da eficiência da educação empreendedora. Além disso, diferentemente de estudos anteriores, a presente pesquisa não se limita a estudar o efeito de uma única ação pedagógica, mas focaliza um conjunto destas ações naquilo que se denomina atividades educacionais de formação em empreendedorismo (AEFE). Em termos da contribuição prática, os resultados derivados deste estudo têm o potencial de indicar a efetividade da implementação de atividades de fomento ao empreendedorismo, em cursos de nível superior.

Segundo Laviere (2010), nos cursos de Administração, no Brasil, existe uma tendência para a formação do egresso, tendo-se como referência preparar funcionários para carreiras em grandes empresas. As diferentes perspectivas na formação tradicional em Administração e a formação com traços empreendedores têm ocasionado a necessidade de se buscarem modelos pedagógicos apropriados de AEFE que atendam à formação empreendedora, compatível com as habilidades e as atitudes próprias ao perfil empreendedor (Peterson \& Limbu, 2010; Ruskovaara et al., 2010). O objetivo deste artigo é, portanto, analisar as diferenças no perfil empreendedor de estudantes que participaram de AEFE e estudantes que não participaram. Para alcançar o objetivo deste trabalho, foi testada uma escala de medição do perfil empreendedor desenvolvida e validada por Schmidt e Bohnenberger (2009). 


\section{Referencial Teórico}

O ensino do Empreendedorismo tem apresentado uma gama de formas heterogêneas em seu processo pedagógico. Duas diferentes áreas têm conduzido a educação empreendedora, dessa maneira, diversificando sua respectiva pedagogia. Enquanto uma área aborda a educação sobre o empreendedorismo, a outra enfoca a educação para o empreendedorismo (Lautenschläger \& Haase, 2011). Na literatura recente, percebe-se maior preocupação na educação voltada para ensinar o empreendedorismo com o propósito de formar empreendedores atuantes, indo além do conhecimento teórico do tema (Cheung \& Au, 2010; Elmuti, Khoury, \& Omran, 2012; Giovanela, Gouveia, Frâncio, \& Dalfano, 2010; Peterson \& Limbu, 2010).

Lautenschläger e Haase (2011) ressaltam que existem aspectos do empreendedorismo que podem ser fáceis de ensinar e outros não. Habilidades e competências como criatividade, inovação, proatividade, tomada de decisão e propensão ao risco, afirmam os autores, são aspectos que ainda não se encontram devidamente respaldados por métodos de ensino adequados. Estudiosos da educação empreendedora têm defendido uma linha pedagógica mais voltada para a prática como mais apropriada para o ensino do Empreendedorismo. A aula tradicional expositiva pode ser utilizada para repassar aspectos teóricos e culturais do empreendedorismo, direcionando os demais aspectos da ação empreendedora para métodos e recursos pedagógicos mais dinâmicos (Honig, 2004; Peterson \& Limbu, 2010; Ruskovaara et al., 2010).

No contexto da formação empreendedora, o comportamento esperado do estudante vai ao encontro dos conhecimentos, habilidades e atitudes que compõem o sujeito empreendedor. Dessa forma, os objetivos propostos de ensino-aprendizagem devem levar o estudante a ser capaz de: conscientizarse sobre o que é o empreendedorismo, ser criativo, ser inovador, descobrir uma oportunidade, planejar e abrir um novo negócio, fazer previsões, assumir riscos, persistir, lidar com conflitos, adquirir autocontrole, aprender com a tomada de decisão, erros e acertos, trabalhar em equipe, formar uma rede de contatos e administrar o negócio de forma sustentável (Cheung \& Au, 2010; Degen, 2009; Elmuti et al., 2012; Fayolle, 2006; Honig, 2004; Ilander, 2010; Knotts, 2011; Rae, 2000; Ruskovaara et al., 2010).

Nesse contexto, a European Commission Enterprise and Industry Directorate-General (European Commission, 2008) apresenta uma estrutura para a educação empreendedora no ensino superior dividida em três objetivos: (a) desenvolver espírito empreendedor entre os estudantes, (b) treinar estudantes para abrir uma empresa e administrá-la, (c) desenvolver habilidades empreendedoras necessárias para identificar e explorar oportunidades de negócios. Uma percepção esquemática pode ser vista na Figura 1, em que se expõem os três pilares que sustentam os objetivos do ensino do Empreendedorismo.

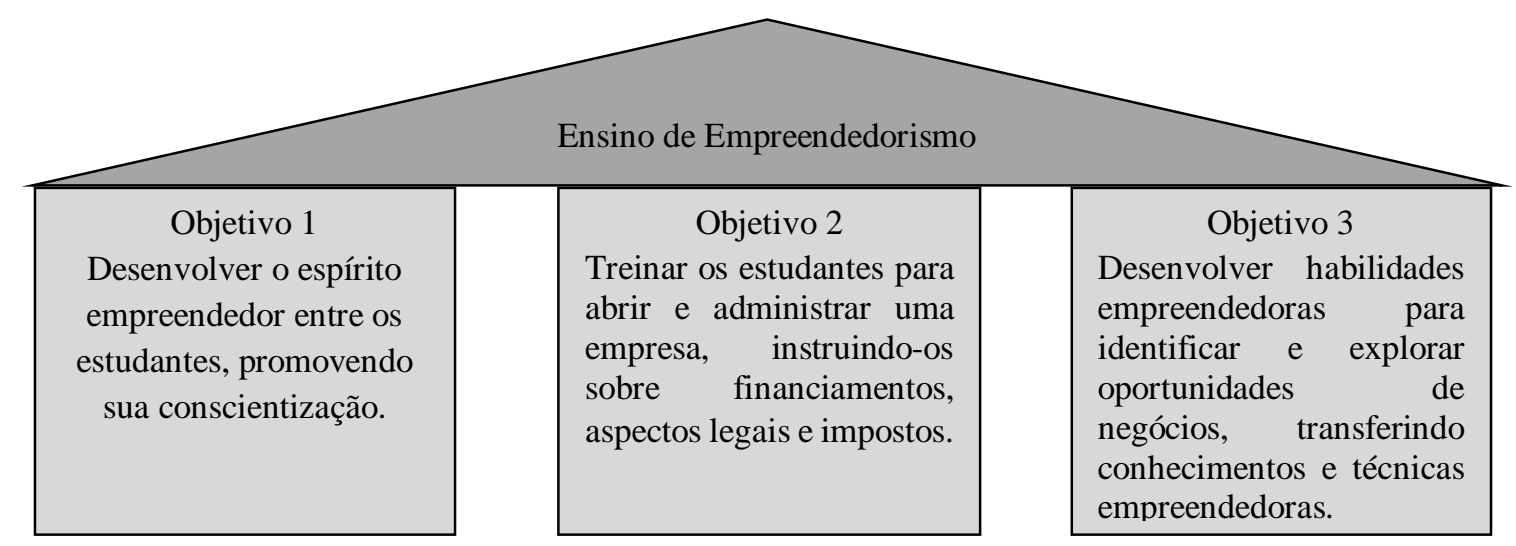

Figura 1. Pilares dos Objetivos do Ensino do Empreendedorismo.

Fonte: Baseado na proposta da European Commission Enterprise and Industry Directorate-General. (2008). Entrepreneurship in higher education, especially in non-business studies: final report of the expert group (p. 22). Recuperado de http://ec.europa.eu/enterprise/policies/sme/files/support_measures/training_education/entr_highed_en.pdf 
A formação empreendedora tem uma característica multidisciplinar (Boyles, 2012). Para alcançar os diferentes objetivos, faz-se necessário traçar um plano de ensino que adapte a metodologia pedagógica ao contexto da aprendizagem esperada. Nessa perspectiva, diferentes opções de métodos, técnicas e recursos são encontradas na literatura como forma de se promover o processo de ensinoaprendizagem da formação empreendedora (Degen, 2009; Dolabela, 2008; Dornellas, 2008; Hisrich et al., 2009; Honig, 2004; Ilander, 2010; Knotts, 2011; Kuratko, 2005; Schmidt, Soper, \& Facca, 2012).

Entre as opções pedagógicas de ensino-aprendizagem são citadas palestras, recomendações de leituras, estudos de caso, visita a empresas, brainstorming, simulações e projetos desenvolvidos em grupos (Dolabela, 2008; Henrique \& Cunha, 2008). Existem, também, planos de negócios, entrevistas com empreendedores, uso de filmes (Kuratko, 2005) e jogos sobre empreendedorismo (Ruskovaara et $a l .$, 2010). Esta miríade de opções pedagógicas indicadas por estes autores é resultado da especificidade da formação empreendedora, a qual requer modelos de ensino que permitam ao estudante desenvolver as habilidades e técnicas empreendedoras por meio de experiências práticas durante sua aprendizagem (Giovanela et al., 2010; Knotts, 2011; Ruskovaara et al., 2010).

Uma vez que a formação empreendedora envolve uma série de conteúdos de aprendizagem, fazse necessário organizar as diversas metodologias com as respectivas aplicações pedagógicas. Dessa forma, à luz das propostas pedagógicas pesquisadas nos periódicos científicos nacionais e internacionais, juntamente com as constantes nas obras dos autores da bibliografia nacional, é possível relacionar e descrever as respectivas aplicações dos principais métodos, técnicas e recursos utilizados no ensino do Empreendedorismo. As obras didáticas: Empreendedorismo: transformando ideias em negócios (Dornelas, 2008), O empreendedor: empreender como opção de carreira (Degen, 2009), Empreendedorismo: dando asas ao espírito empreendedor (Chiavenato, 2004), Oficina do empreendedor (Dolabela, 2008), Empreendedorismo (Hisrich et al., 2009), Ferramentas para empreendedores: ferramentas e técnicas para expandir seus negócios (Luecke, 2009), Manual do empreendedor: como construir um empreendimento de sucesso (Mendes, 2009), Criação de novos negócios: Empreendedorismo para o século 21 (Dornelas et al., 2010) e O fenômeno do Empreendedorismo (Leite, 2012), são as referências bibliográficas consultadas na metodologia do ensino. Somado a isso, têm-se os relatórios da European Commission Enterprise and Industry e periódicos científicos nacionais e internacionais. Na Tabela 1, estão descritas as principais atividades educacionais de formação em empreendedorismo (AEFE) sugeridas para o ensino do Empreendedorismo:

Tabela 1

\section{Principais Métodos, Técnicas e Recursos Pedagógicos no Ensino de Empreendedorismo}

\begin{tabular}{ll}
\hline Métodos, Técnicas e Recursos & Aplicações \\
\hline Aulas expositivas & $\begin{array}{l}\text { Transferir conhecimentos sobre o Empreendedorismo, as características } \\
\text { pessoais do empreendedor, os processos de inovação, fontes de recursos, } \\
\text { financiamentos e aspectos legais de pequenas empresas. }\end{array}$ \\
Visitas e contatos com empresas & $\begin{array}{l}\text { Estimular o network e incitar o estudante a sair dos limites da IES para } \\
\text { entender o funcionamento de mercado na vida real. Desenvolver visão de } \\
\text { mercado. }\end{array}$ \\
Plano de negócios & $\begin{array}{l}\text { Desenvolver as habilidades de planejamento, estratégia, marketing, } \\
\text { contabilidade, recursos humanos, comercialização. Desenvolver a } \\
\text { habilidade de avaliação do novo negócio, analisando o impacto da inovação } \\
\text { no novo produto ou serviço. Construir habilidade de avaliar e dimensionar } \\
\text { riscos do negócio pretendido. }\end{array}$ \\
Construção da habilidade de pensamento crítico e de avaliação de cenários e \\
negócios. Desenvolver a habilidade de interpretação e definição de \\
contextos associados ao Empreendedorismo.
\end{tabular}




\section{Tabela 1 (continuação)}

\begin{tabular}{ll}
\hline Métodos, Técnicas e Recursos & Aplicações \\
\hline Trabalhos teóricos em grupo & $\begin{array}{l}\text { Construção da habilidade de aprender coletivamente. Desenvolver a } \\
\text { habilidade de pesquisar, dialogar, integrar e construir conhecimentos, } \\
\text { buscar soluções e emitir juízos de valor na realização do documento escrito. }\end{array}$ \\
Trabalhos práticos em grupo & $\begin{array}{l}\text { Construção da habilidade de atuar em equipe. Desenvolver a habilidade de } \\
\text { planejar, dividir e executar tarefas em grupo, de passar e receber críticas } \\
\text { construtivas. Ampliar a integração entre o saber e o fazer. }\end{array}$
\end{tabular}

Grupos de discussão

Desenvolver a habilidade de testar novas ideias. Desenvolver a capacidade de avaliar mudanças e prospectá-las como fonte de oportunidades.

\section{Brainstorming}

Construção da habilidade de concepção de ideias, prospecção de oportunidades, reconhecendo-as como oportunidades empreendedoras. Estimular o raciocínio intuitivo para criação de novas combinações de serviços ou produtos, transformando-as em inovações.

Seminários e palestras com empreendedores

Criação de empresa

Transferir conhecimentos das experiências vividas por empreendedores desde a percepção e criação do produto, abertura do negócio, sucessos e fracassos ocorridos na trajetória empreendedora.

Transpor as informações do plano de negócios e estruturar os contextos necessários para a formalização. Compreender várias etapas da evolução da empresa. Desenvolver a habilidade de organização e planejamento operacional.

Aplicação de provas dissertativas Testar os conhecimentos teóricos dos estudantes e sua habilidade de comunicação escrita.

Atendimento individualizado

Desenvolver a habilidade de comunicação, interpretação, iniciativa e resolubilidade. Aproximar o estudante do cotidiano real vivido nos pequenos negócios.

Trabalhos teóricos individuais Construção da habilidade de geração de conhecimento individualizado, estimulando a autoaprendizagem. Induzir o processo de autoaprendizagem.

Trabalhos práticos individuais

Construção da habilidade da aplicação dos conhecimentos teóricos individuais, estimulando a autoaprendizagem. Estimular a capacidade laboral e de autorrealização.

Criação de produto

Filmes e vídeos

Desenvolver habilidade de criatividade, persistência, inovação e senso de avaliação.

Desenvolver a habilidade do pensamento crítico e analítico, associando o contexto assistido com o conhecimento teórico. Estimular a discussão em grupo e o debate de ideias.

Jogos de empresas e simulações Desenvolver a habilidade de criar estratégias de negócios, solucionar problemas, trabalhar e tomar decisões sob pressão. Aprender pelos próprios erros. Desenvolver tolerância ao risco, pensamento analítico, comunicação intra e intergrupais.

Sugestão de leituras

Prover ao estudante teoria e conceitos sobre o Empreendedorismo. Aumentar a conscientização do ato empreendedor.

Incubadoras

Proporcionar ao estudante espaço de motivação e criação da nova empresa, desenvolvendo múltiplas competências, tais como habilidades de liderança, organizacionais, tomada de decisão e compreender as etapas do ciclo de vida das empresas. Estimular o fortalecimento da network com financiadores, fornecedores e clientes.

Competição de planos de negócios

Desenvolver habilidades de comunicação, persuasão e estratégia.

Desenvolver capacidade de observação, percepção e aplicação de melhorias no padrão de qualidade dos planos apresentados. Estimular a abertura de empresas mediante os planos vencedores.

Nota. Fonte: elaborado pelos autores. 
Não obstante, em paralelo às propostas metodológicas de ensino do Empreendedorismo, existe a preocupação em se avaliar a efetiva aprendizagem do estudante nesta área do conhecimento. Para isso, diversas maneiras de avaliação têm sido apresentadas a fim de se medir o impacto causado nos estudantes após concluírem os estudos de empreendedorismo (Lautenschläger \& Haase, 2011). Nesse sentido, encontram-se na literatura métodos direcionados a medir o nível de empreendedorismo entre os estudantes, variando da medição do perfil empreendedor, da intenção empreendedora, do potencial empreendedor, entre outros aspectos (Mcgee, Peterson, Mueller, \& Sequeira, 2009; Santos, Caetano, \& Curral, 2010; Schmidt \& Bohnenberger, 2009; Wilson, Kickul, Marlino, Barbosa, \& Griffiths, 2009).

\section{Medição da aprendizagem do empreendedorismo via perfil empreendedor}

No caso específico da avaliação da aprendizagem, devido à característica multifacetada do empreendedorismo, são encontradas na literatura diferentes abordagens que tratam da medição desta aprendizagem (Wilson, Kickul, \& Marlino, 2007). Essas propostas de avaliação podem ser associadas às conjunturas do processo educacional desenvolvido na formação empreendedora. Alternativas de medição, como abertura de novas empresas, intenção de iniciar um negócio próprio, autoeficácia, perfil empreendedor, orientação empreendedora, potencial empreendedor e aptidão empreendedora, são encontradas na literatura como formas de avaliação da eficiência da educação empreendedora (Cubico, Bortaloni, Favretto, \& Sartori, 2010; Mcgee et al., 2009; Santos et al., 2010; Schmidt \& Bohnenberger, 2009; Silva, Gomes, \& Correia, 2009).

A avaliação da aprendizagem do empreendedorismo entre estudantes de graduação tem sido conduzida por diferentes modelos que, em sua maioria, tentam medir o resultado dessa aprendizagem, relacionando-a com o ato de abertura do negócio próprio ou a intenção disso. Nessa perspectiva, Boyles (2012) argumenta que a medição por abertura ou intenção de abrir empresas não tem sido uma forma adequada para avaliar o resultado do ensino de Empreendedorismo para graduandos ou recémgraduados. Este autor aponta que, em suas pesquisas, a maioria dos empreendedores pesquisados abriu sua empresa a partir dos 35 anos de idade, sobretudo, em razão da necessidade de adquirir experiência profissional antes de iniciar o próprio negócio. Desse modo, aduz o autor, ao utilizar-se esta forma avaliativa em graduandos ou recém-graduados, o resultado da avaliação da aprendizagem poderia ficar distorcido.

Nessa mesma linha de raciocínio, observa-se que, em vários estudos, a intenção de iniciar um negócio próprio também tem sido uma modalidade singular utilizada para detectar o comportamento empreendedor em indivíduos (Thompson, 2009). Conquanto este modelo avaliativo seja comumente utilizado por pesquisadores nesta área do conhecimento, seu enfoque tende a ultrapassar as barreiras das Instituição de Ensino Superior (IES). Isso é possível ser percebido uma vez que, neste método de avaliar a intenção de iniciar o próprio negócio, outros fatores também são considerados, como fatores ambientais e fatores pessoais, incluindo-se idade, sexo, experiência laboral, parentesco com empreendedores e nível educacional (Izquierdo \& Buelens, 2008; Liñán \& Chen, 2009). Dessa forma, o foco no resultado da aprendizagem pode ser confundido ou desvirtuado por fatores que vão além da competência do processo do ensino do Empreendedorismo nos cursos de graduação.

Por sua vez, o perfil empreendedor tem sido objeto de pesquisas acadêmicas como forma de identificar as características e competências comuns encontradas em indivíduos que atuam de acordo com as prerrogativas empreendedoras relatadas na literatura. Essas pesquisas têm revelado um conjunto dessas características que vêm sendo encontradas constantemente em grande parte dos empreendedores pesquisados (Lopes \& Souza, 2005; Olakitan \& Ayobami, 2011). Um nível mais elevado de concentração destas características e competências em determinados indivíduos tem sido usado como uma maneira de diferenciar grupos com perfil empreendedor mais elevado em comparação a outros grupos pesquisados (Oosterbeek, Praag, \& Ijsselstein, 2010).

Assim, diante de uma perspectiva de formação empreendedora para estudantes universitários, um modelo confiável de medição deste perfil pode captar as diferentes manifestações do perfil empreendedor presentes entre grupos distintos de estudantes. Nesse contexto, pesquisas têm sido 
realizadas com estudantes brasileiros em que se abordaram o perfil empreendedor como instrumento de medição da aprendizagem em empreendedorismo. Ferreira e Mattos (2003) realizaram pesquisa com 432 estudantes de cursos de graduação em Administração na Região Metropolitana de Recife, avaliando o grau de aprendizagem por meio da alteração do perfil empreendedor entre estudantes que participaram de práticas didático-pedagógicas em empreendedorismo. O perfil empreendedor desse estudo foi composto pelas qualidades: Autoconhecimento; Criatividade; Proatividade; Autonomia na tomada de decisão; Aceitação ao risco e Construção de mudança.

Em outra pesquisa, Schmidt e Bohnenberger (2009) estudaram a base conceitual do perfil empreendedor. Estes autores construíram uma estrutura com as características determinantes do perfil empreendedor, representada na Tabela 2, a seguir:

Tabela 2

\section{Características do Perfil do Empreendedor}

\begin{tabular}{ll}
\hline Características & Descrição \\
\hline Autoeficaz & $\begin{array}{l}\text { É a estimativa cognitiva que uma pessoa tem das suas capacidades de mobilizar } \\
\text { motivação, recursos cognitivos e cursos de ação necessários para exercitar controle } \\
\text { sobre eventos na sua vida. }\end{array}$ \\
$\begin{array}{l}\text { Assume riscos } \\
\text { calculados }\end{array}$ & $\begin{array}{l}\text { Pessoa que, diante de um projeto pessoal, relaciona e analisa as variáveis que podem } \\
\text { influenciar o seu resultado, decidindo, a partir disso, a continuidade do projeto. }\end{array}$ \\
Planejador & Pessoa que se prepara para o futuro. \\
$\begin{array}{l}\text { Detecta } \\
\text { oportunidades }\end{array}$ & $\begin{array}{l}\text { Habilidade de capturar, reconhecer e fazer uso efetivo de informações abstratas, } \\
\text { Persistente }\end{array}$ \\
Capacitas e em constante mudança. \\
sociais, em projetos de retorno incerto. \\
Gociável
\end{tabular}

Nota. Fonte: Schmidt, S., \& Bohnenberger, M. C. (2009). Perfil empreendedor e desempenho organizacional (pp. 454-455). Revista de Administração Contemporânea, 13(3), 450-467. Recuperado de http://www.scielo.br/pdf/rac/v13n3/v13n3a07.pdf. doi: 10.1590/S1415-65552009000300007

O estudo de Schmidt e Bohnenberger (2009) teve como objetivo a construção e validação de um instrumento de medição do perfil empreendedor e sua relação com o desempenho organizacional. $\mathrm{O}$ instrumento de medição foi iniciado com a definição de oito constructos oriundos das características do perfil empreendedor, assim descritos pelos autores: (a) Autoeficaz (AE); (b) Assume riscos calculados (AR); (c) Planejador (PL); (d) Detecta oportunidades (DO); (e) Persistente (PE); (f) Sociável (SO); (g) Inovador (IN); e (h) Líder (LI). Itens de medição foram criados para cada constructo, resultando em um questionário estruturado por meio de uma escala Likert. O questionário foi aplicado e respondido por 1.113 estudantes universitários.

O processo de validação ocorreu por meio de uma análise fatorial, em que se confirmou uma estrutura latente de seis fatores, com KMO de 0,852 e variância total explicada de 56,4\%. Também, foi detectada concentração entre os itens que se referiam à autoeficácia, detecção de oportunidades e persistência. Com base na literatura, os autores verificaram que estas três características juntas compõem o conceito de Autorrealização. Dessa forma, o fator 1 ficou denominado de Autorrealização. Os demais fatores foram assim descritos: fator 2 - Líder; fator 3 - Planejador; fator 4 - Inovador; fator 5 - Assume riscos; e fator 6 - Sociável. Com o teste de confiabilidade composta dos constructos, ficaram asseguradas a validação e a confiabilidade do instrumento de medição, como expressa a afirmação de Schmidt e 
Bohnenberger (2009, p. 464): “foi utilizado um método robusto de validação do instrumento, o que abre uma série de possibilidades quanto a sua utilização". A Tabela 3 apresenta os fatores e seus respectivos itens.

Tabela 3

\section{Itens Representativos dos Fatores}

\begin{tabular}{|c|c|c|}
\hline Fatores & Itens & Variáveis \\
\hline \multirow{5}{*}{$\begin{array}{l}\text { Fator 1- } \\
\text { Autorrealização }\end{array}$} & Frequentemente, detecto oportunidades de negócio no mercado. & V1 \\
\hline & $\begin{array}{l}\text { Creio que tenho uma boa habilidade em detectar oportunidades de negócio no } \\
\text { mercado. }\end{array}$ & V6 \\
\hline & Tenho controle sobre os fatores para minha plena realização profissional. & $\mathrm{V} 22$ \\
\hline & $\begin{array}{l}\text { Profissionalmente, considero-me uma pessoa muito mais persistente que as } \\
\text { demais. }\end{array}$ & V4 \\
\hline & $\begin{array}{l}\text { Sempre encontro soluções muito criativas para problemas profissionais com os } \\
\text { quais me deparo. }\end{array}$ & V8 \\
\hline \multirow[t]{5}{*}{ Fator 2- Líder } & Tenho um bom plano para minha vida profissional. & $\mathrm{V} 2$ \\
\hline & $\begin{array}{l}\text { Frequentemente, sou escolhido como líder em projetos ou atividades } \\
\text { profissionais. }\end{array}$ & V7 \\
\hline & Frequentemente, as pessoas pedem minha opinião sobre assuntos de trabalho. & V5 \\
\hline & As pessoas respeitam minha opinião. & V9 \\
\hline & Relaciono-me muito facilmente com outras pessoas. & $\mathrm{V} 12$ \\
\hline \multirow{3}{*}{$\begin{array}{l}\text { Fator } 3 \text { - } \\
\text { Planejador }\end{array}$} & No meu trabalho, sempre planejo muito bem tudo o que faço. & V11 \\
\hline & $\begin{array}{l}\text { Sempre procuro estudar muito a respeito de cada situação profissional que } \\
\text { envolva algum tipo de risco. }\end{array}$ & V10 \\
\hline & Tenho os assuntos referentes ao trabalho sempre muito bem-planejados. & V13 \\
\hline \multirow[t]{2}{*}{ Fator 4 - Inovador } & Prefiro um trabalho repleto de novidades a uma atividade rotineira. & V16 \\
\hline & Gosto de mudar minha forma de trabalho sempre que possível. & V15 \\
\hline \multirow{4}{*}{$\begin{array}{l}\text { Fator } 5 \text { - Assume } \\
\text { riscos }\end{array}$} & Incomoda-me muito ser pego de surpresa por fatos que eu poderia ter previsto. & V14 \\
\hline & $\begin{array}{l}\text { Eu assumiria uma dívida de longo prazo, acreditando nas vantagens que uma } \\
\text { oportunidade de negócio me traria. }\end{array}$ & V17 \\
\hline & $\begin{array}{l}\text { No trabalho, normalmente, influencio a opinião de outras pessoas a respeito de } \\
\text { um determinado assunto. }\end{array}$ & V20 \\
\hline & Admito correr riscos em troca de possíveis benefícios. & V19 \\
\hline \multirow[t]{3}{*}{ Fator 6 - Sociável } & Meus contatos sociais influenciam bem pouco a minha vida profissional. & V18 \\
\hline & Os contatos sociais que tenho são muito importantes para minha vida pessoal. & $\mathrm{V} 21$ \\
\hline & $\begin{array}{l}\text { Conheço várias pessoas que me poderiam auxiliar profissionalmente, caso eu } \\
\text { precisasse. }\end{array}$ & V3 \\
\hline
\end{tabular}

Nota. Fonte: Schmidt, S., \& Bohnenberger, M. C. (2009). Perfil empreendedor e desempenho organizacional (pp. 460-461). Revista de Administração Contemporânea, 13(3), 450-467. Recuperado de http://www.scielo.br/pdf/rac/v13n3/v13n3a07.pdf. doi: 10.1590/S1415-65552009000300007

Assim, foi escolhido o instrumento de medição destes autores por considerá-lo adequado para a estrutura deste presente trabalho. A seção seguinte trata das escolhas metodológicas do estudo. 


\section{Metodologia}

Esta pesquisa caracteriza-se como descritiva quanto aos fins, e de campo, quanto aos meios (Vergara, 2009). Segundo Hair, Babin, Money e Samouel (2005), a pesquisa descritiva descreve alguma situação por meio da mensuração de um evento ou atividade. Ainda, para estes autores, isso pode ser conseguido com o uso de estatísticas descritivas obtidas de análises de dados capturados por uma estrutura especificamente criada para medir as características descritas na questão de pesquisa. Esta pesquisa também é caracterizada como quantitativa, de modo que as investigações têm natureza empírica, cuja finalidade é analisar as características de grupos de indivíduos mensuradas por meio de variáveis quantificadas nos dados coletados (Marconi \& Lakatos, 2006).

O estudo tem delimitação de corte transversal, pois os dados são coletados em uma única vez, o que representa o instantâneo do momento da coleta (Cooper \& Schindler, 2003). Vergara (2009) define a pesquisa de campo como "uma investigação empírica realizada no local onde ocorre ou ocorreu o fenômeno ou que dispõe de elementos para explicá-lo" (p. 43). Assim, esta pesquisa enquadra-se nesta definição em face da investigação ocorrer entre os estudantes presentes nas respectivas IESs selecionadas para o desenvolvimento deste trabalho científico. Diante do exposto, a pesquisa é do tipo: descritiva, quantitativa, de campo e transversal. Tem como finalidade descrever as características percebidas entre grupos de estudantes universitários, analisadas via dados empíricos, coletados instantaneamente por meio de variáveis específicas presentes em questionário estruturado, e utilizadas para mensurar os aspectos delineados no objetivo deste estudo.

O universo desta pesquisa é composto por estudantes universitários matriculados em Curso de Administração de Empresas em Instituições de Ensino Superior (IES) localizadas na cidade de Fortaleza, capital do Ceará. Fortaleza é a quinta maior cidade do Brasil, com a população estimada em dois milhões e meio de habitantes. Apresentou Produto Interno Bruto (PIB) de 31,7 bilhões de reais, em 2009. Em 2010 , Fortaleza possuía apenas $29,6 \%$ da população em empregos formais, número baixo, quando comparado a outras capitais brasileiras, por exemplo, Belo Horizonte, com 57,1\%, e Florianópolis, com 60,4\% (Instituto de Pesquisa e Estratégia Econômica do Ceará [IPECE], 2012). A abertura de novas empresas, por meio do empreendedorismo, aumenta a oferta de empregos, tendendo a melhorar a taxa de empregos formais em Fortaleza. Sobre este aspecto, dados levantados pela Secretaria de Finanças do município mostram que Fortaleza é a quarta cidade do Brasil em termos de formalização individual, superada apenas pelo Rio de Janeiro, São Paulo e Curitiba (O Povo Jornal de Hoje, 2010). Além disso, o Ceará é o segundo estado do nordeste em número de empreendedores individuais.

A amostra é composta por estudantes pertencentes a quatro IES distribuídas entre duas IESs públicas, a Universidade Federal do Ceará (UFC) e a Universidade Estadual do Ceará (UECE), e duas IESs particulares, a Universidade de Fortaleza (UNIFOR) e o Centro Universitário Christus (UNICHRISTUS). As quatro IESs apresentam cursos de Administração consolidados, com mais de 10 anos de funcionamento. Dessa forma, a amostra foi constituída por estudantes de cada IES, perfazendo um total de 407 indivíduos. Os dados foram coletados pelo método survey, utilizando-se uma escala métrica de Likert com sete pontos para a mensuração do perfil empreendedor. O objetivo da coleta de dados foi proporcionar informações que permitissem análise consistente entre grupos de estudantes que participaram ou não de AEFE em suas respectivas IESs. A intensidade do nível de concordância é determinada mediante a variação de 1 para discordo totalmente e 7 para concordo totalmente (Cooper \& Schindler, 2003).

O instrumento de coleta de dados usado consiste de um questionário estruturado, autoadministrado e composto de 22 itens que se referem à escala de medição do perfil empreendedor validada por Schmidt e Bohnenberger (2009). Segundo Vergara (2009), os tratamentos dos dados fazem a correlação entre os objetivos da pesquisa e a forma como serão atingidos. Assim, os dados foram tratados, inicialmente, por uma análise estatística descritiva, seguida por teste de consistência de escala, análise fatorial e análise de variância multivariada. O Software Statistical Package for the Social Sciences (SPSS) foi o recurso utilizado no tratamento e análise dos dados. As 22 variáveis que compõem 
a escala do perfil empreendedor são, portanto, as variáveis observáveis desta pesquisa. Estas são as variáveis submetidas à análise fatorial que, uma vez agrupadas, representam as seis dimensões da escala. A Figura 2 é a representação do procedimento descrito.

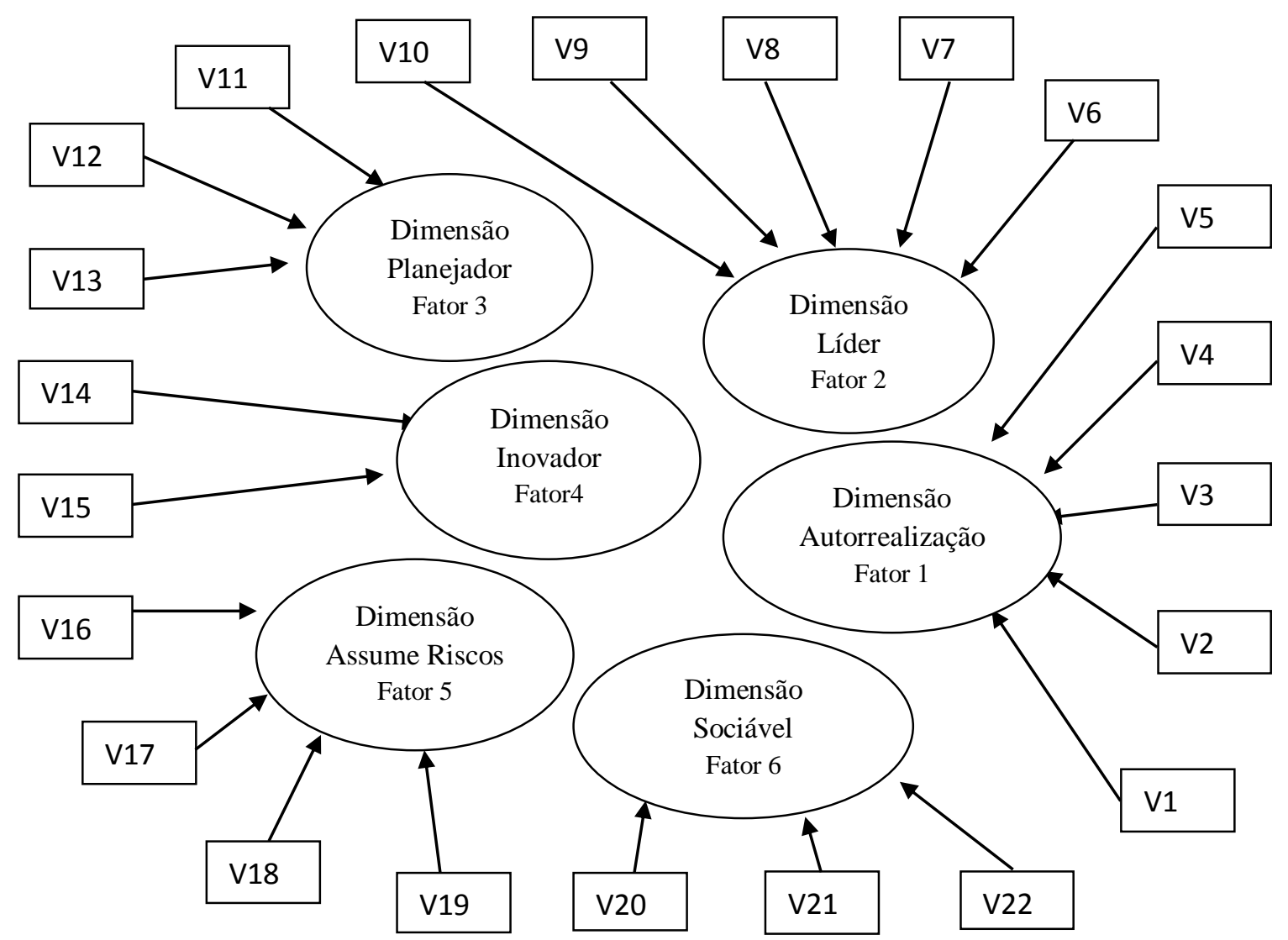

Figura 2. Variáveis e Dimensões da Escala do Perfil Empreendedor de Schmidt e Bohnenberger (2009). Fonte: Fonte: Elaborado pelos autores a partir Schmidt, S., \& Bohnenberger, M. C. (2009). Perfil empreendedor e desempenho organizacional (p. 462). Revista de Administração Contemporânea, 13(3), 450-467. Recuperado de http://www.scielo.br/pdf/rac/v13n3/v13n3a07.pdf. doi: 10.1590/S1415-65552009000300007

O Alfa de Cronbach foi utilizado como instrumento de mensuração da confiabilidade da escala de medição do perfil empreendedor proposta por Schmidt e Bohnenberger (2009). O valor estatístico do Alfa de Cronbach varia entre 0 e 1, de modo que, quanto mais próximo de 1, maior a fidedignidade das dimensões do constructo captada pelos itens que o compõem. Valores acima de 0,6 são aceitos como o mínimo adequado para a confiabilidade (Corrar, Paulo, \& Dias, 2011). A análise fatorial é um recurso estatístico de análise multivariada de interdependência baseado em combinações lineares de variáveis que sintetizam as variáveis originais por meio de suas relações latentes (Hair, Babin, Money, \& Samouel, 2005).

A Análise de Variância Multivariada (MANOVA) é uma técnica estatística utilizada em grupos de amostras independentes para avaliar as diferenças entre as médias destes grupos. A MANOVA verifica diferenças de grupos de variáveis categóricas (independentes) quanto aos seus impactos sobre diversas variáveis métricas (dependentes) ao mesmo tempo (Hair et al., 2005). O teste de diferenças em médias de grupos aplica-se a esta pesquisa devido ao objetivo de avaliar as alterações quanto ao perfil empreendedor em grupos de alunos que participaram e que não participaram de AEFE. Desse modo, é possível avaliar se as diferenças entre os níveis médios dos grupos captados pela survey são significativas entre os grupos e dentro dos grupos. Os efeitos dos impactos encontrados são a chave para se chegar à resposta da pesquisa. A hipótese nula, apresentada a seguir, foi utilizada para conduzir esta pesquisa. Com a rejeição desta, a hipótese alternativa é comprovada (Hair et al., 2005). 
H0 (1): Não há diferença entre os níveis médios das dimensões do perfil empreendedor entre estudantes que participaram e não participaram de atividades educacionais de formação em Empreendedorismo (AEFE).

As informações dos estudantes que permitem testar a hipótese nula desta pesquisa foram adquiridas por meio de questionário estruturado. A fim de garantir maior efetividade na coleta das informações, os estudantes foram abordados, pessoalmente, em sala de aula, para responderem aos questionários, sempre acompanhados por monitores responsáveis pela distribuição e recolhimento dos formulários. Os meses de setembro e outubro de 2012 foram os escolhidos para a aplicação de tais questionários. Cooper e Schindler (2003) recomendam a realização de um pré-teste em instrumentos de coleta de dados com o propósito de se verificar a adequação deste ao público-alvo. Assim, antes da aplicação do questionário desta pesquisa, um pré-teste de campo com 15 estudantes foi realizado a fim de captar previamente qualquer desvio ou imprevisto que tendesse a prejudicar a informação buscada e o processo de coleta dos dados. As AEFE foram mensuradas por meio das alterações encontradas nos níveis médios das características componentes do perfil empreendedor.

\section{Resultados e Discussões}

\section{Análise estatística}

A coleta de dados ocorreu em outubro e novembro de 2012, no ambiente das quatro IESs já citadas: UNICHRISTUS, UECE, UFC e UNIFOR. Neste processo, contou-se com a participação de 407 estudantes respondentes dos cursos de administração das respectivas IESs. Destes, 242 participaram de AEFE, atingindo cerca de $60 \%$ do total. A participação de cada IES ocorreu conforme a Tabela 4, obtendo-se uma distribuição quase homogênea, $52,8 \%$ e 47,2\%, entre as IES públicas, UECE e UFC, e as privadas, UNICHRISTUS e UNIFOR.

Tabela 4

Distribuição de Estudantes Respondentes por IES

\begin{tabular}{ccccc}
\hline IES & UNICHRISTUS & UECE & UFC & UNIFOR \\
\hline $\mathrm{N}^{\circ}$ de estudantes & 110 & 146 & 69 & 82 \\
\hline
\end{tabular}

Nota. Fonte: dados da pesquisa.

As características socioacadêmicas dos estudantes respondentes revelam que a proporção entre homens e mulheres é bem próxima (50,9\% e 48,2\%), tendo a maioria dos estudantes idade até 25 anos $(77,7 \%)$, o que demonstra a jovialidade do grupo. A participação por ano acadêmico foi bem distribuída, com $17,9 \%$ de representantes do $1^{\circ}$ ano do curso, $31,7 \%$ do $2^{\circ}$ ano, $29,0 \%$ do $3^{\circ}$ ano e $20,4 \%$ do $4^{\circ}$ e último ano. Para os procedimentos de verificação dos dados sobre as características socioacadêmicas, foi realizado um levantamento dos casos de missing values e de outliers da amostra coletada. Para estas variáveis, obteve-se 5 missing values e nenhum outliers, o que representou 1,2\% da amostra.

Com o emprego da técnica de análise fatorial, objetivou-se verificar a possibilidade de condensar a informação contida nas variáveis originais da escala do perfil empreendedor em um conjunto menor de fatores (Hair, Black, Babin, Anderson, \& Tatham, 2009). A partir disso, foi possível comparar as novas dimensões encontradas com as previstas por Schmidt e Bohnenberger (2009). Antes de iniciar o processo da análise fatorial, foi realizada uma análise nos dados das variáveis que compõem a escala métrica. Hair, Black, Babin, Anderson e Tatham (2009) recomendam analisar os casos de dados perdidos (missing values) e casos de dados com observações atípicas (outliers). Desse modo, por meio da técnica listwise, chegou-se ao número de 13 casos perdidos entre as 22 variáveis formadoras da escala. 
O tamanho final utilizado da amostra $(\mathrm{N}=394)$ pode ser classificado como adequado, uma vez que a relação entre o tamanho da amostra e o número de variáveis analisadas (22) ultrapassa a proporção de $10 \div 1$ (neste caso, obteve-se 17,9), sugerida por Hair et al. (2009). A análise fatorial exploratória foi realizada usando-se o método de extração dos componentes principais e o método ortogonal Varimax na rotação dos fatores.

Além do tamanho da amostra, testes estatísticos foram executados a fim de se avaliar a aplicabilidade da amostra para a análise fatorial. A adequação da amostra foi medida por meio do teste de Kaiser-Meyer-Olkin (KMO), sendo indicados valores acima de 0,50 como o mínimo aceitável nesse teste. Associado a isso, o teste de esfericidade de Bartlett indica a presença de correlações significantes entre os itens da escala, não devendo o teste de significância ultrapassar 0,05 (Corrar et al., 2011). O KMO apresentou valor de 0,858, semelhante ao da pesquisa de Schmidt e Bohnenberger (2009), de 0,852, ambos maiores que 0,50. Já o teste de Bartlett apresentou significância de 0,001. O teste estatístico da matriz de correlação anti-imagem avalia a adequação de cada variável ao modelo de análise fatorial. Valores abaixo de 0,50 indicam baixo poder de explicação dos fatores em relação a cada variável (Corrar et al., 2011; Hair et al., 2009). Com exceção de uma variável, os resultados apontaram valores acima de 0,7 , evidenciando a boa adequação para a aplicação da análise fatorial.

A variância total dos fatores atingiu 56,2\%. Malhotra (2012) recomenda que este valor seja acima de 60\%. Entretanto, Hair et al. (2009) acrescentam que, pesquisas em ciências sociais, nas quais as informações tendem a ser menos precisas, é possível considerar uma solução que explique menos que $60 \%$ como satisfatória. Assim, considerando-se que a variância total explicada na análise fatorial efetuada por Schmidt e Bohnenberger (2009) atingiu 56,4\%, o valor encontrado nesta pesquisa também foi aceito.

O Alfa de Cronbach $(\alpha)$ foi a medida utilizada para medir o coeficiente de confiabilidade de escalas múltiplas. Para pesquisas exploratórias, o valor mínimo sugerido para o $\alpha$ é de 0,60 (Hair et al., 2009). Desse modo, os resultados obtidos nesta análise estatística revelam Alfa de Cronbach não padronizado de 0,843 e padronizado de 0,853 ; considerado de boa consistência por Pestana e Gageiro (2008), que indicam o intervalo de 0,8 a 0,9 para esta classificação.

O método da Análise de Componentes Principais (ACP) foi utilizado para determinação dos fatores. Por meio da rotação ortogonal Varimax, foi possível encontrar a carga dos fatores de cada variável em cada fator (Corrar et al., 2011). A distribuição final dos fatores mostrou um conjunto de seis fatores formados pelas respectivas variáveis. As cargas fatoriais resultantes apresentaram valores acima de $\pm 0,50$, tidas como significativas em amostras de tamanho acima de 150, como denotam Hair et al. (2009). O total de seis fatores corresponde ao total proposto por Schmidt e Bohnenberger (2009) na escala do perfil empreendedor. As variáveis agrupadas em cada fator denominaram as seis dimensões latentes dos componentes da escala do perfil empreendedor, conforme a Tabela 5.

Tabela 5

\section{Dimensões da Análise Fatorial}

\begin{tabular}{ccc}
\hline Fator & Dimensão & Variáveis \\
\hline $\mathbf{1}$ & Líder & V09, V07, V20, V08, V05 \\
$\mathbf{2}$ & Autorrealização & V22, V04, V02, V03 \\
$\mathbf{3}$ & Planejador & V11, V13, V10, V14 \\
$\mathbf{4}$ & Inovador & V01, V16, V15, V06 \\
$\mathbf{5}$ & Assume Riscos & V19, V17, V12 \\
$\mathbf{6}$ & Sociável & V18, V21 \\
\hline
\end{tabular}

Nota. Fonte: dados da pesquisa. 
Em relação à composição das dimensões da escala proposta por Schmidt e Bohnenberger (2009), foi possível notar certas alterações nos agrupamentos das variáveis para a formação dos fatores. Nesse sentido, conquanto as dimensões finais tenham permanecido as mesmas, algumas variáveis migraram de dimensão, como foi o caso da variável V03, que migrou da dimensão Sociável para a Autorrealização e da variável V02, que migrou da dimensão Líder para a Autorrealização. Considerando que a dimensão Autorrealização engloba uma característica também componente do perfil empreendedor, a Autoeficácia (Cubico et al., 2010). E, que, para McGee, Peterson, Mueller e Sequeira (2009), a Autoeficácia está relacionada à crença pessoal do indivíduo em sua capacidade de realizar um trabalho profissional, assim, mobilizando recursos cognitivos a ações necessárias para exercitar controle sobre eventos de sua vida. Tanto a variável V03 quanto a V02 podem ser reconhecidas como uma atitude de Autoeficácia, justificando-as na dimensão Autorrealização.

Nas variáveis V20 e V14, ocorreu uma migração para a composição original dos constructos previstos por Schmidt e Bohnenberger (2009). A V20, que migrou da dimensão Assume Riscos para a Líder, retornou ao antigo perfil de líder apontado por estes autores, em que se enfatiza a característica de influenciar as pessoas, prevista nessa variável. Da mesma forma, a variável V14 migrou da dimensão Assume Riscos para a dimensão Planejador. No estudo de Schmidt e Bohnenberger (2009), esta variável estava associada originalmente ao perfil planejador, o que justifica a adequação dessas migrações.

Outra caracterização detectada remete à formação da dimensão Inovador, que passou de duas variáveis para quatro, na versão desta pesquisa. As duas novas variáveis V01 e V06 abordam sobre a detecção de oportunidades de negócio no mercado. Esta abordagem apresenta certa convergência com a dimensão Inovador, uma vez que, para Schmidt e Bohnenberger (2009), o sujeito inovador relaciona ideias, fatos, necessidades e demandas de mercado de forma criativa. Além disso, Maciel (2009) e Shane e Venkataramam (2000) afirmam que o termo oportunidade, quando associado ao empreendedorismo, refere-se ao processo criativo de novas concepções, ou inovações, que alteram a forma tradicional utilizada no mercado. Assim, as variáveis V01 e V06 justificam-se como componentes da dimensão Inovador.

A nova configuração das variáveis na composição dos constructos pode ser vista como uma formatação apropriada, considerando-se os estudos de Ferreira e Mattos (2003) e Schmidt e Bohnenberger (2009). Com efeito, a nova estruturação vai ao encontro do que se preconiza na literatura, no que tange aos constructos de Autorrealizador, Líder, Planejador e Inovador (Dolabela, 2008; Lopes \& Souza, 2005).

\section{Discussão dos resultados}

Com a realização da análise fatorial, foram definidas as seis dimensões do perfil empreendedor. Cada dimensão participa, a partir desta etapa da pesquisa, como uma variável latente, cujos índices são constituídos pela média aritmética (escores médios) das variáveis componentes (Pestana \& Gageiro, 2008). Dessa forma, as seis variáveis latentes (dimensões) apresentam-se com os índices formados pela respectiva pontuação média dos itens das variáveis que as integram, representadas conforme a Tabela 6 , a seguir. Nesta, mostram-se quais itens formam as diferentes dimensões do perfil empreendedor e a forma de cálculo dos seus respectivos índices. 
Tabela 6

Índices das Dimensões - Forma de Composição

\begin{tabular}{cc} 
Dimensão & Índices \\
\hline Líder & $(\mathrm{V} 09+\mathrm{V} 07+\mathrm{V} 20+\mathrm{V} 08+\mathrm{V} 05) / 5$ \\
Autorrealização & $(\mathrm{V} 22+\mathrm{V} 04+\mathrm{V} 02+\mathrm{V} 03) / 4$ \\
Planejador & $(\mathrm{V} 11+\mathrm{V} 13+\mathrm{V} 10+\mathrm{V} 14) / 4$ \\
Inovador & $(\mathrm{V} 01+\mathrm{V} 16+\mathrm{V} 15+\mathrm{V} 06) / 4$ \\
Assume Riscos & $(\mathrm{V} 19+\mathrm{V} 17+\mathrm{V} 12) / 3$ \\
Sociável & $(\mathrm{V} 18+\mathrm{V} 21) / 2$ \\
\hline
\end{tabular}

Nota. Fonte: dados da pesquisa.

De acordo com o postulado por Hair et al. (2009), a técnica de análise MANOVA pode utilizar o conjunto de variáveis métricas latentes oriundas da análise fatorial como variáveis dependentes. Desse modo, o teste da hipótese foi realizado conforme a variável categórica selecionada para a formação dos grupos propostos no estudo. Além de permitir a análise do conjunto das dimensões do perfil empreendedor sobre estes grupos, a MANOVA também permite avaliar o impacto individual de cada dimensão sobre os mesmos. Para a utilização da MANOVA, Hair et al. (2009) apontam três suposições a fim de se proporcionar maior validade aos testes multivariados: independência de observações, homocedasticidade nos grupos e normalidade. Além disso, estes autores também ressaltam a importância dos tamanhos amostrais adequados para as fases de análise da MANOVA.

A hipótese aborda a análise da participação de AEFE entre os estudantes pesquisados. Nessa perspectiva, foi criada uma variável V23, que se constitui como a variável categórica independente que forma os dois grupos analisados nesta etapa. Os grupos foram divididos entre os que responderam 1 , para o sim, e 2, para o não. Após análise dos missings values, o total de repostas reduziu-se a $\mathrm{N}=391$. Os grupos formaram-se com 234 participantes de AEFE e 157 não participantes. O tamanho da amostra dos grupos atende as premissas de Hair et al. (2009) no que se refere à proporção do tamanho: 234 / 157 $=1,49$, menor que 1,50 indicado pelos autores. Também atende no que se refere ao tamanho mínimo de 20 observações por célula.

A suposição da independência de observações está caracterizada pelo plano de amostragem aleatória dos estudantes respondentes nos diversos semestres das quatro IES pesquisadas, conforme postulam Hair et al. (2009). A homocedasticidade refere-se à homogeneidade das matrizes de variânciacovariância entre os grupos. A análise destas matrizes foi realizada por meio do teste de Levene, que consiste de testes univariados, e do teste $\mathrm{M}$ de box, que consiste de teste de igualdade das matrizes entre os grupos.

Os resultados obtidos no teste de Levene revelam que, entre as seis dimensões, cinco mostraram resultados não significantes (valores acima de 0,05), confirmando a homocedasticidade. Somente a dimensão Inovador apresentou valor significante $(0,001)$, apontando possível existência de heteroscedasticidade para esta variável. Todavia, diante dos tamanhos amostrais relativamente grandes, associados à presença da homocedasticidade nas demais cinco dimensões, ações corretivas para a dimensão Inovador podem ser dispensadas, seguindo critérios adotados por Hair et al. (2009). A Tabela 7 elenca os valores do teste de Levene das seis dimensões discutidas. 
Tabela 7

Teste de Levene para Teste de Homocedasticidade das Dimensões do Perfil Empreendedor

\begin{tabular}{ccc}
\hline Dimensão & F & Sig. \\
\hline LÍDER & 2,824 &, 094 \\
AUTORREALIZAÇÃO & 1,015 &, 314 \\
PLANEJADOR &, 002 &, 962 \\
INOVADOR & 10,782 &, 001 \\
ASSUMERISCOS &, 623 &, 430 \\
SOCIÁVEL & 1,750 &, 187 \\
\hline
\end{tabular}

Nota. Fonte: dados da pesquisa SPSS.

Os resultados do teste $\mathrm{M}$ de box apontaram um valor significante na diferença entre as matrizes de variância-covariância entre os dois grupos $(0,000)$. Por esse teste, não foi possível aceitar o pressuposto da homocedasticidade multivariada. No entanto, para Hair et al. (2009), essa violação tem impacto mínimo se os grupos apresentam aproximadamente o mesmo tamanho, isto é, o tamanho do maior grupo não pode exceder 1,5 vezes o tamanho do menor. Desse modo, uma vez que os tamanhos das amostras encontram-se nesta faixa sugerida, foi considerada uma não gravidade das violações.

Quanto à normalidade, as variáveis dependentes (dimensões) não apresentaram distribuição normal. No entanto, segundo Hair et al. (2009), violações dessa suposição têm pouco impacto em amostras maiores. Para testar se existe intercorrelação significante entre todas as dimensões, foi realizado o teste de esfericidade de Bartlett. Os resultados com $\alpha=0,000$ confirmam que há um grau significante de intercorrelação entre as seis dimensões.

Feitas as análises e considerações dos pressupostos, partiu-se para a análise multivariada de variância. A princípio, foram utilizados testes multivariados para avaliar o conjunto das variáveis dependentes quanto a diferenças entre as médias dos dois grupos. Os testes utilizados foram o critério de Pillai, Lambda de Wilks, traço de Hoteling e maior raiz de Roy, sugeridos por Hair et al. (2009). Os quatro testes indicaram elevada diferença significante entre os dois grupos avaliados, confirmando que o conjunto das dimensões difere entre os grupos. Os resultados também revelaram poder estatístico 0,996 , acima do 0,80 recomendado por estes autores, indicando que os tamanhos amostrais e o tamanho do efeito do tratamento foram suficientes para garantir o poder estatístico da MANOVA. A Tabela 8 apresenta os resultados dos testes estatísticos multivariados.

Tabela 8

Testes Multivariados para Teste da Influência da Participação em AEFE nos Níveis Médios do Perfil Empreendedor

\begin{tabular}{lcccc}
\hline Variável independente & Teste estatístico & Valor & F & Sig. \\
\hline \multirow{4}{*}{ Participação em AEFE } & Pillai's Trace &, 077 & 5,376 &, 000 \\
& Wilks' Lambda &, 923 & 5,376 &, 000 \\
& Hotelling's Trace &, 084 & 5,376 &, 000 \\
& Roy'sLargest Root &, 084 & 5,376 &, 000 \\
\hline
\end{tabular}

Nota. Fonte: dados da pesquisa SPSS.

Testes estatísticos univariados podem ser utilizados para avaliar cada dimensão em separado (Hair et al., 2009). Assim, é possível identificar quais dimensões contribuem para as diferenças gerais 
apresentadas entre os dois grupos. Nessa perspectiva, foi encontrado que as dimensões Líder $(0,101)$ e Sociável $(0,239)$ não apresentaram significância $(p>0,05)$, excluindo-as dos efeitos da participação em AEFE entre os estudantes. As demais dimensões: Autorrealização $(0,000)$, Planejador $(0,008)$, Inovador $(0,000)$ e Assume riscos $(0,001)$ apresentaram elevada significância $(\mathrm{p}<0,05)$ para os dois grupos de estudantes, indicando diferenças significativas nas médias dessas dimensões entre os grupos.

Em relação às dimensões Líder e Sociável, é possível afirmar que ambas também são trabalhadas na formação do administrador nos Cursos de Administração (Laviere, 2010). Dessa maneira, considerando-se que ambos os grupos de estudantes são graduandos em Administração, percebe-se que existe uma dosagem aplicada dessas duas dimensões na formação do administrador, o que pode justificar a não apresentação de diferenças significativas nessas duas dimensões entre os grupos pesquisados. Esta ocorrência também poderia ser vista como um fator positivo para a inclusão do ensino de Empreendedorismo em associação com o ensino de Administração, uma vez que alguns traços do perfil do empreendedor são trabalhados na formação do perfil do administrador.

Por outro lado, embora as dimensões Líder e Sociável não tenham sofrido alterações significativas individualmente, no conjunto das dimensões, as alterações foram significativas. A estatística descritiva traz os dados referentes às médias de cada dimensão perante os dois grupos de estudantes. Nas quatro dimensões em que existiram diferenças significantes entre as medidas, verificou-se que as médias daqueles estudantes que participaram de AEFE são maiores do que as daqueles que não participaram. Com base nesses resultados encontrados coletiva e individualmente, conclui-se que a hipótese nula Ho1 não foi confirmada, assim, indicando que os estudantes que participaram de AEFE apresentam alterações significativas nos níveis médios do perfil empreendedor. As alterações são percebidas positivamente nas quatro dimensões: Autorrealização, Planejador, Inovador e Assume riscos. A Tabela 9 traz os valores das médias de cada grupo das quatro dimensões.

Tabela 9

Diferença nas Dimensões do Perfil Empreendedor Entre Participantes e Não Participantes de AEFE

\begin{tabular}{lccccc}
\hline Dimensão & $\begin{array}{c}\text { Participação } \\
\text { em AEFE }\end{array}$ & Média & Desvio padrão & N & $\begin{array}{c}\text { Diferenças } \\
\text { entre médias }\end{array}$ \\
\hline AUTOREALIZAÇÃO & SIM & 4,9701 & 0,82845 & 234 & $+0,34$ \\
& NAO & 4,6306 & 0,92620 & 157 & \\
& Total & 4,8338 & 0,88371 & 391 & $+0,22$ \\
\hline PLANEJADOR & SIM & 5,2874 & 0,81295 & 234 & \\
& NAO & 5,0621 & 0,82996 & 157 & $+0,33$ \\
INOVADOR & Total & 5,1969 & 0,82619 & 391 & \\
& SIM & 5,0299 & 0,79609 & 234 & $+0,36$ \\
\hline ASSUMERISCOS & NAO & 4,7006 & 1,00058 & 157 & \\
& Total & 4,8977 & 0,89734 & 391 & \\
& SIM & 5,1054 & 0,99224 & 234 & 157 \\
\hline
\end{tabular}

Nota. Fonte: dados da pesquisa SPSS.

Ainda, observando a Tabela 9, repara-se que a dimensão Planejador apresenta a menor diferença entre as médias. Mais uma vez, isso é possível de ser justificado entendendo-se que a referida dimensão também está presente na formação do administrador. Não obstante, essa tendência de crescimento das 
médias das dimensões do perfil empreendedor é também encontrada nos estudos de Ferreira e Mattos (2003) e de Cheung e Au (2010). Nessa perspectiva, diante dos resultados apresentados, é possível afirmar que este crescimento nas médias dos estudantes que participaram de AEFE atesta a eficiência de certos métodos pedagógicos para o ensino e aprendizagem do empreendedorismo em relação a estudantes universitários, desse modo, estando em consonância com o postulado por Degen (2009).

\section{Considerações Finais}

A formação de empreendedores tem estado na pauta das estratégias governamentais nas três esferas públicas: Federais, Estaduais e Municipais. O sujeito empreendedor é aquele que não mede esforços para abrir e administrar seu próprio negócio, gerando emprego e renda para a sociedade. No entanto a sustentabilidade das novas empresas é uma preocupação que permeia o empreendedorismo. Uma possível solução para amenizar essa situação seria a formação de empreendedores mais qualificados no âmbito da gestão. Diante disso, os Cursos de Administração aparecem como parte atenuante desse fenômeno da baixa sustentabilidade das novas empresas.

O empreendedorismo é um fenômeno de ação que exige do empreendedor um protagonismo que faça com que os processos que movem uma empresa sejam comandados por este sujeito. Por se tratar de um processo de ação, existe certa desconfiança quanto à possibilidade de se ensinar as características do empreendedor para pessoas que não as tenham. As discussões sobre esse ponto já avançaram bastante, chegando-se ao novo paradigma que trata da discussão de como se ensinar o empreendedorismo e como avaliar o perfil empreendedor. Sobre este último ponto, trabalhos como o de Schmidt e Bohnenberger (2009) são úteis à medida que desenvolveram métricas de avaliação do perfil empreendedor. Diferente da pesquisa destes autores, que teve o intuito de avaliar a relação entre o perfil e o desempenho organizacional, a presente pesquisa utiliza-se da escala desenvolvida para avaliar a eficiência do processo de ensino-aprendizagem do empreendedorismo.

Nesse contexto, encaixa-se o objetivo deste trabalho, que procurou investigar as transformações ocorridas entre estudantes universitários de Cursos de Administração, do município de Fortaleza, depois de submetidos às atividades educacionais de formação em empreendedorismo (AEFE). O perfil empreendedor foi o atributo utilizado para realizar a pesquisa. Assim, ficou evidenciado que o perfil empreendedor de estudantes que participaram de AEFE apresentou alterações nas dimensões que o compõem em relação aos dos estudantes que não participaram. As dimensões Autorrealização, Planejador, Inovador, Assume Riscos, Líder e Sociável formaram o perfil empreendedor deste trabalho e, dessa maneira, confirmaram a característica multidimensional do sujeito empreendedor. Ademais, a partir desta investigação, foi possível perceber que algumas dimensões do perfil empreendedor sofreram maiores alterações que outras. As dimensões Líder e Sociável, quando analisadas individualmente, não apresentaram alterações significativas entre os dois grupos. Seria isso um forte indício que estas dimensões estão sendo bem trabalhadas nos Cursos de Administração, a ponto de se direcionar mais ênfase na formação empreendedora para as demais dimensões? As dimensões Autorrealização, Planejador, Inovador e Assume Riscos, por sua vez, foram as que sofreram alterações significativas, atestando que o ensino do empreendedorismo pode desenvolver as características do sujeito empreendedor em estudantes universitários, mesmo antes de se abrir um negócio próprio.

Embora tenham sido apresentados métodos e técnicas usualmente utilizados no ensino do empreendedorismo, não foi possível, nesta pesquisa, identificar quais desses recursos proporcionam maior efeito na alteração do perfil empreendedor do estudante de administração. Esta é uma primeira sugestão para pesquisas futuras. Além disso, novas avenidas de pesquisas devem ser abertas para incluírem a influência de efeitos moderadores entre a educação empreendedora e o perfil empreendedor. Entre estes efeitos, sugere-se a investigação de variáveis como o pertencimento ou não a famílias cujos pais são empreendedores e a experiência prévia dos discentes no mercado de trabalho. 
Finalmente, é importante frisar as limitações deste trabalho. Em primeiro lugar, registre-se que a pesquisa limitou-se a estudantes de quatro IESs localizadas em um único município, em um corte transversal, não sendo recomendada a generalização dos resultados. Em segundo lugar, o que se observa na literatura indica que o perfil empreendedor teve sua construção baseada em sujeitos empreendedores reais, e não em estudantes universitários. Assim, deve-se ressaltar que os resultados deste trabalho foram baseados nas percepções de graduandos, diferentes de outras pesquisas realizadas com estudantes graduados que abriram o próprio negócio. Dessa forma, sugere-se o desenvolvimento de outras pesquisas a serem realizadas com egressos que abriram negócio próprio, comparando o perfil desse grupo com o dos estudantes pesquisados neste trabalho.

\section{Referências}

Acs, Z. J. (2006). How is entrepreneurship good for economic growth? Innovations: Technology, Governance, Globalization, 1(1), 97-107. doi:10.1162/itgg.2006.1.1.97

Bae, T. J., Qian, S., Miao, C., \& Fiet, J. O. (2014). The relationship between entrepreneurship education and entrepreneurial intentions: a meta-analytic review. Entrepreneurship: Theory and Practice, 38(2), 217-254. doi: 10.1111/etap.12095

Boyles, T. (2012). 21st century knowledge, skills, and abilities and entrepreneurial competence: a model for undergraduate entrepreneurship education. Journal of Entrepreneurship Education, 15(1), 41-55.

Casson, M. (1982). The entrepreneur. Totowa, New Jersey: Barnes \& Noble Books.

Cheung, C., \& Au, E. (2010). Running a small business by students in a secondary school: its impact on learning about entrepreneurship. Journal of Entrepreneurship Education, 13(1), 45-63.

Cooper, D. R., \& Schindler, P. S. (2003). Métodos de pesquisa em Administração (7a ed.). Porto Alegre: Bookman.

Corrar, L. J., Paulo, E., \& Dias, J. M., Filho (2011). Análise multivariada: para cursos de administração, ciências contábeis e economia. São Paulo: Atlas.

Cubico, S., Bortaloni, E., Favretto, G., \& Sartori, R. (2010). Describing the entrepreneurial profile aptitude test (TAI). International Journal Entrepreneurship and Small Business, 11(4), 424-435.

Degen, R. J. (2009). O empreendedor: empreender como opção de carreira. São Paulo: Pearson Prentice Hall.

Dolabela, F. (2008). Oficina do empreendedor. Rio de Janeiro: Sextante.

Dornelas, J. C. A. (2008). Empreendedorismo: transformando ideias em negócios (3a ed.). Rio de Janeiro: Elsevier.

Dornelas, J., Timmons, J. A., \& Spinelli, S. (2010). Criação de novos negócios: empreendedorismo para o século 21 (Adap. da 8a ed. americana, C. Mello, Trad.). São Paulo: Elsevier. (Obra original publicada em 2009)

Elmuti, D., Khoury, G., \& Omran, O. (2012). Does entrepreneurship education have a role in developing entrepreneurial skills and venture's effectiveness? Journal of Entrepreneurship Education, 15(1) 83-98.

European Commission Enterprise and Industry Directorate-General. (2008). Entrepreneurship in higher education, especially in non-business studies: final report of the expert group. Recuperado de 
http://ec.europa.eu/enterprise/policies/sme/files/support_measures/training_education/entr_high ed_en.pdf

Fayolle, A. (2006). Essay on the nature of entrepreneurship education. Recuperado de http://www1.kmu.unisg.ch/rencontres/RENC2006/topics06/A/rencontres_2006_fayolle.pdf

Ferreira, P. G. G., Mattos, P. L. C. L. (2003, setembro). Empreendedorismo e práticas didáticas nos cursos de graduação em administração: os estudantes levantam o problema. Anais do Encontro Nacional da Associação Nacional de Pós-Graduação e Pesquisa em Administração, Atibaia, SP, Brasil, 27.

Filion, L. J. (1999). Empreendedorismo: empreendedores e proprietários-gerentes de pequenos negócios. Revista de Administração, 34(2), 5-28.

Giovanela, A., Gouveia, A. B. C. T. de, Frâncio, S., \& Dalfano, O. (2010). As características da disciplina de empreendedorismo em Instituições de Ensino Superior do Estado de Santa Catarina. Revista Gestão Universitária na América Latina, 3(1), 69-84. doi: 10.5007/19834535.2010v3n1p69

Hair, J. F., Jr., Babin, B., Money, A. H., \& Samouel, P. (2005). Fundamentos de métodos de pesquisa em administração (L. Ribeiro, Trad.). Porto Alegre: Bookman. (Obra original publicada em 2003)

Hair, J. F., Jr., Black, W. C., Babin, B., Anderson, R. E., \& Tatham, R. L. (2009). Análise multivariada de dados (6a ed., A. Sant'Anna, Trad.). Porto Alegre: Bookman. (Obra original publicada em 2006)

Henrique, D. C., \& Cunha, S. K. (2008). Práticas didático-pedagógicas no ensino de empreendedorismo em cursos de graduação e pós-graduação nacionais e internacionais. Revista de Administração Mackenzie, 9(5), 112-136.

Hisrich, R. D., Peters, M. P., \& Shepherd, D. A. (2009). Empreendedorismo (7a ed.). Porto Alegre: Bookman.

Honig, B. (2004). Entrepreneurship education: toward a model of contingency-based business planning. Academy of Management Learning and Education, 3(3), 258-273. doi: 10.5465/AMLE.2004.14242112

Ilander, G. P. B. (2010). The use of feature films to promote entrepreneurship. International Journal Information and Operation Management Education, 3(3), 284-302. doi: 10.1504/IJIOME.2010.033551

Instituto de Pesquisa e Estratégia Econômica do Ceará. (2012). Perfil básico municipal. Recuperado de http://www.ipece.ce.gov.br/publicacoes/perfi_basico/index_perfil_basico.htm

Izquierdo, E., \& Buelens, M. (2008, July). Competing models of entrepreneurial intentions: the influence of entrepreneurial self-efficacy and attitudes. Proceedings of the Internationalizing Entrepreneurship Education and Trainning, Oxford, Ohio, USA, 17.

Knotts, T. L. (2011). The SBDC in the classroom: providing experiential learning opportunities at different entrepreneurial stages. Journal of Entrepreneurship Education, 14(1), 25-38.

Kuratko, D. F. (2005). The emergence of entrepreneurship education: development, trends, and challenges. Entrepreneurship Theory and Practice, 29(5), 577-598. doi: 10.1111/j.15406520.2005.00099.x

Lautenschläger, A., \& Haase, H. (2011). The myth of entrepreneurship education: seven arguments against teaching business creation at universities. Journal of Entrepreneurship Education, 14(1), $147-161$. 
Laviere, C. (2010). Educação empreendedora? In R. M. A. Lopes (Org.), Educação empreendedora: conceitos, modelos e práticas (pp. 1-16). Rio de Janeiro: Elsevier.

Leite, E. (2012). O fenômeno do empreendedorismo. São Paulo: Saraiva.

Liñán, F., \& Chen, Y. (2009). Development and cross-cultural application of a specific instrument to measure entrepreneurial intentions. Entrepreneurship Theory and Practice, 33(3), 593-617. doi: $10.1111 /$ j.1540-6520.2009.00318.x

Lopes, G. S., Jr., \& Souza, E. C. L. (2005). Atitude empreendedora em proprietários-gerentes de pequenas empresas: construção de um instrumento de medida. Revista Eletrônica de Administração, 11(6), 1-14.

Luecke, R. (2009). Ferramentas para empreendedores: ferramentas e técnicas para desenvolver e expandir seus negócios (3a ed., R. Vinagre, Trad.). Rio de Janeiro: Record. (Obra original publicada em 2005).

Maciel, C. O. (2009). Comportamento empreendedor e capacidades organizacionais: hierarquização e mensuração de seus efeitos no desempenho de empresas de pequeno porte. Revista Alcance, 16(1), 26-44.

Malhotra, N. K. (2012). Pesquisa de marketing: uma orientação aplicada (6a ed.). Porto Alegre: Bookman.

Marconi, M. A., \& Lakatos, E. M. (2006). Técnicas de pesquisa: planejamento e execução de pesquisas, amostragens e técnicas de pesquisa, elaboração, análise e interpretação de dados (6a ed.). São Paulo: Atlas.

Martes, A. C. B. (2010). Weber e Schumpeter: a ação econômica do empreendedor. Revista de Economia Política, 30(2), 254-270. doi: 10.1590/S0101-31572010000200005

Martin, B. C., McNally, J. J., \& Kay, M. J. (2013). Examining the formation of human capital in entrepreneurship: a meta-analysis of entrepreneurship education outcomes. Journal of Business Venturing, 28(2), 211-224. doi: 10.1016/j.jbusvent.2012.03.002

Mcgee, J. E., Peterson, M., Mueller, S. L., \& Sequeira, J. M. (2009). Entrepreneurial self-efficacy: refining the measure. Entrepreneurship Theory and Practice, 4(33) 965-988. doi: 10.1111/j.15406520.2009.00304.x

Mendes, J. (2009). Manual do empreendedor: como construir um empreendimento de sucesso. São Paulo: Atlas.

Murphy, P. J., Liao, J., \& Welsch, H. P. (2006). A conceptual history of entrepreneurial thought. Journal of Management History, 12(1), 12-35. doi: 10.1108/13552520610638256

Olakitan, O. O., \& Ayobami, A. P. (2011). An investigation of personality on entrepreneurial success. Journal of Emerging Trends in Economics and Management Sciences, 2(2), 95-103.

Oosterbeek, H., Praag, M. van, \& Ijsselstein, A. (2010). The impact of entrepreneurship education on entrepreneurship skills and motivation. European Economic Review, 54(1) 442-454. doi: 10.1016/j.euroecorev.2009.08.002

O Povo Jornal de Hoje. (2010, agosto, 6). Fortaleza é a quarta capital em formalização de empreendedores. Recuperado de http://www.opovo.com.br/app/opovo/economia/2010/06/08/noticiasjornaleconomia,2007701/fo rtaleza-e-a-quarta-capital-em-formalizacao-de-empreendedores.shtml 
Pestana, M. H., \& Gageiro, J. N. (2008). Análise de dados para ciências sociais: a complementaridade do SPSS (5a ed.). Lisboa: Sílabo.

Peterson, R. T., \& Limbu, Y. (2010). Student characteristics and perspectives in entrepreneurship courses: a profile. Journal of Entrepreneurship Education, 13(1), 65-83.

Rae, D. (2000). Understanding entrepreneurial learning: a question of how? International Journal of Entrepreneurial Behaviour \& Research, 6(3), 145-159. doi: 10.1108/13552550010346497

Ruskovaara, E., Pihkala, T., Rytkölä, T., \& Seikkula-Leino, J. (2010, August). Studying teachers' teaching methods and working approaches in entrepreneurship education. Procedings of the ESU Conference, Tartu, Estonia, 22.

Santos, S. C., Caetano, A., \& Curral, L. (2010). Atitude dos estudantes universitários face ao empreendedorismo: como identificar o potencial empreendedor? Revista Portuguesa e Brasileira de Gestão, 9(4), 2-14.

Schmidt, S., \& Bohnenberger, M. C. (2009). Perfil empreendedor e desempenho organizacional. Revista de Administração Contemporânea, 13(3), 450-467. Recuperado de http://www.scielo.br/pdf/rac/v13n3/v13n3a07.pdf. doi: 10.1590/S1415-65552009000300007

Schmidt, J. S., Soper. J. C., \& Facca, T. M. (2012) .Creativity in the entrepreneurship classroom. Journal of Entrepreneurship Education, 15(1) 123-131.

Shane, S., \& Venkataraman, S. (2000). The promise of entrepreneurship as a field of research. The Academic of Management Review, 25(1), 217-226.

Silva, M. A. O. M. da, Gomes, L. F. A. M., \& Correia, M. F. (2009). Cultura e orientação empreendedora: uma pesquisa comparativa entre empreendedores em incubadoras no Brasil e em Portugal. Revista de Administração Contemporânea, 13(1) 57-71. Recuperado de http://www.scielo.br/pdf/rac/v13n1/a05v13n1.pdf. doi: 10.1590/S1415-65552009000100005

Thompson, E. R. (2009). Individual entrepreneurial intent: constructo clarification and development of an internationally reliable metric. Entrepreneurship Theory and Practice, 33(3), 669-492. doi: 10.1111/j.1540-6520.2009.00321.x

Vergara, S. C. (2009). Projetos e relatórios de pesquisa em administração (10a ed.). São Paulo: Atlas.

Wilson, F., Kickul, J., \& Marlino, D. (2007). Gender, entrepreneurial self-efficacy, and entrepreneurial career intentions: implications for entrepreneurship education. Entrepreneurship Theory and Practice, 31(3), 387-406. doi: 10.1111/j.1540-6520.2007.00179.x

Wilson, F., Kickul, J., Marlino, D., Barbosa, S. D., \& Griffiths M. D. (2009). An analysis of the role of gender and self-efficacy in developing female entrepreneurial interest and behavior. Journal of Developmental Entrepreneurship, 14(2), 105-119. doi: 10.1142/S1084946709001247 